OPEN ACCESS

Edited by:

Chunqiao Song,

Nanjing Institute of Geography and Limnology (CAS), China

Reviewed by: Chunyu Dong,

Sun Yat-sen University, China Fangfang Yao, University of Colorado Boulder, United States

Rijan Bhakta Kayastha, Kathmandu University, Nepal

*Correspondence: Yongjian Ding dyj@/zb.ac.cn

Shiqiang Zhang zhangsq@nwu.edu.cn

Specialty section: This article was submitted to

Cryospheric Sciences,

a section of the journal

Frontiers in Earth Science

Received: 21 June 2020 Accepted: 28 October 2020 Published: 04 December 2020

Citation:

Ding $Y$, Zhang $S$, Chen $R$, Han $T$, Han H, Wu J, Li X, Zhao Q, Shangguan D, Yang Y, Liu J, Wang S, Qin J and Chang Y (2020) Hydrological

Basis and Discipline System of Cryohydrology: From a Perspective of

Cryospheric Science.

Front. Earth Sci. 8:574707. doi: 10.3389/feart.2020.574707

\section{Hydrological Basis and Discipline System of Cryohydrology: From a Perspective of Cryospheric Science}

Yongjian Ding ${ }^{1,2,3,4 *}$, Shiqiang Zhang ${ }^{5,6 *}$, Rensheng Chen ${ }^{3}$, Tianding Han ${ }^{1}$, Haidong Han $^{2,3}$ Jinkui $W^{3}{ }^{3}$, Xiangying $L_{i}^{5,6}$, Qiudong Zhao ${ }^{1,2,3}$, Donghui Shangguan ${ }^{1,2}$, Yong Yang ${ }^{3}$, Junfeng Liu $^{3}$, Shengxia Wang ${ }^{3}$, Jia Qin ${ }^{3}$ and Yaping Chang ${ }^{3}$

\begin{abstract}
${ }^{1}$ State Key Laboratory of Cryospheric Science, Northwest Institute of Eco-Environment and Resources, Chinese Academy of Sciences, Lanzhou, China, ${ }^{2}$ China-Pakistan Joint Research Center on Earth Science, Chengdu, China, ${ }^{3}$ Key Laboratory of Ecohydrology of Inland River Basin, Chinese Academy of Sciences, Lanzhou, China, ${ }^{4}$ University of Chinese Academy Sciences, Beijing, China, ${ }^{5}$ Shaanxi Key Laboratory of Earth Surface System and Environmental Carrying Capacity, Northwest University, Xi'an, China, ${ }^{6}$ College of Urban and Environmental Sciences, Northwest University, Xi'an, China
\end{abstract}

Initially, cryohydrology was referred to as hydrology involving low temperatures, for example, the hydrological study of snow, ice, frozen ground, and cold water. This discipline broadened with the development of cryospheric science and now involves hydrological processes of various cryosphere elements systematically coupled with river basin hydrological processes. However, limited studies have introduced the characteristics and discipline connotations of cryohydrology from a perspective of cryospheric science. Here, we reviewed the evolution of the connotations of cryohydrology and analyzed its hydrological basis and discipline system. Three major conclusions were drawn. (1) Cryohydrology was developed based on traditional hydrology for a single element of the cryosphere and focuses on the hydrological functions of the cryosphere and its impact on the water cycle and water supply to other spheres. (2) The hydrological basis of cryohydrology can be summarized as water conservation, runoff recharge, and hydrological regulation. In detail, the water conservation function is primarily expressed as "source of freshwater" and "cold and wet islands," the runoff recharge function is concerned with water supply, and the regulation function is effective at intraand inter-annual scales. (3) The core research issues of cryohydrology are research methods, hydrological processes, watershed functions, and regional impact. The important characteristics of cryohydrology are frequent water phase transitions and high variability across spatial and temporal scales. Cryohydrology aims to deepen the understanding of the theoretical and cognitive levels of its mechanisms and processes, accurately quantify the hydrological functions of the basin, and promote understanding of the ecological and environmental impacts of the cryosphere.

Keywords: cryohydrology, hydrological function, discipline system, cryospheric science, cold region hydrology 


\section{INTRODUCTION}

The cryosphere refers to the negative temperature zone of the surface of the Earth, which mostly exists in the form of solid water (Steffen et al., 2012). The elements of the cryosphere primarily include glaciers, ice sheets, frozen ground, snow cover, sea ice, river ice, and lake ice (IPCC, 2013). The interaction between the cryosphere and the hydrosphere is an important hydrological process affecting the Earth's climate (Slaymaker and Kelly, 2009; French and Slaymaker, 2012; National Academy of Sciences, 2012; Yao et al., 2012; Qin et al., 2018), which in turn affects the global sea level and global water-cycle processes (Ding et al., 2017). Therefore, the cryosphere is unique and plays a critical role in global water cycles (Qin et al., 2018).

Under the intensified impact of climate change, in the past decade, the hydrological impacts of the cryosphere have been increasing from the Arctic (Li et al., 2010) to the Tibetan Plateau (Immerzeel et al., 2010; Yao et al., 2019), from the Andes (Masiokas et al., 2010) to the Alps (Bavay et al., 2013; Pellicciotti et al., 2014), from the endorheic river basins (Wang et al., 2009; Zhao et al., 2015) to Siberia (Liljedahl et al., 2016; Kalyuzhnyi and Lavrov, 2017), and from highlatitude oceans to the global sea level (IPCC, 2013). Therefore, the hydrological processes of the cryosphere have become a popular topic within water science for climate change, focusing on global sea level change and the concept of "water towers," for several large rivers and their downstream basins (e.g., Georg et al., 2010; Immerzeel et al., 2010, 2019; Sorg et al., 2012; Biemans et al., 2019; Ye and Lau, 2019).

From the perspective of disciplinary systems, previous studies on cryosphere water issues focused on the hydrological processes of an individual element of the cryosphere, such as glacial hydrology (Yang, 1991; Singh, 2001; Irvine-Fynn et al., 2011), permafrost hydrology (Woo, 2012), and snow hydrology (Singh, 2001; DeWalle and Rango, 2008; Ye and Lau, 2019). For example, research on glacial hydrology primarily involves glacier melt, runoff generation, and the role of glacial runoff in the watershed (Ding et al., 2017; Immerzeel et al., 2019; Tang et al., 2019). With the increasing impact of global warming on the cryosphere, the hydrological processes of different cryosphere elements and their impacts often occur simultaneously in the same watershed or region (Ding et al., 2017). Water issues related to the cryosphere can no longer be resolved from the process and impact of a single cryosphere element. It is necessary to examine the water problems of the cryosphere from the integrated perspective of cryospheric science, which can be called cryospheric hydrology, or cryohydrology.

Initially, cryohyrdrology was referred to as hydrology at low temperatures, for example the hydrological study of snow, ice, frozen ground, and cold water (Woo, 2019). However, the discipline connotation of cryohydrology needs to be broadened from the perspective of cryospheric science. To accurately understand the hydrological effects of different cryosphere elements and the overall hydrological process of the basin under the influence of climate change, it is necessary to consider the hydrological processes of various cryosphere elements systematically and couple them with river basin hydrological processes. This is critical for properly responding to climate change and satisfying the social and economic needs of cryosphere water issues. The integrated view of different hydrological processes of the cryosphere is the core idea behind the term cryohydrology.

Although the term cryohydrology has been mentioned or used in some studies (Phillips et al., 2013; Singh, 2017; Woo, 2019), few studies have named it as an independent discipline system integrating the common and different hydrological characteristics of cryosphere elements. In this study, by condensing the core academic thoughts behind cryohydrology, we attempt to comprehensively construct its research framework from the succession of the discipline, the common hydrological characteristics of the cryosphere, to the research content, and the discipline's constituents. This study will help understand the integrated hydrological functions of the different elements of the cryosphere at the regional or global scale. The paper is organized as follows: Introduction introduced the background and the aim of the research; Developing the Cryohydrology Discipline describes the development of the cryohydrology discipline including the origin of the cryohydrology concept, and its relationship and difference with cold region hydrology; Hydrological Basis of Cryohydrology analyzes the hydrological basis of cryohydrology including water conservation, runoff recharge, and hydrological regulation; Discipline System of Cryohydrology depicts the discipline system of cryohydrology; and Summary and Perspective presents summary and perspective.

\section{DEVELOPING THE CRYOHYDROLOGY DISCIPLINE}

\section{Origin of the Cryohydrology Concept}

Cryospheric hydrology studies have focused on a single element of the cryosphere for a long time. For example, snowmelt runoff modelling started in the 1960 s based on papers by Martinec (1960), Martinec (1965). Before that, also in the USA, snow hydrological investigations had already been carried out (US Army Snow Hydrology, 1956). The earliest attempts at quantifying the glacial meltwater proportion of watershed yield were achieved by leveraging glacier mass balance, climate, and discharge data (Collier, 1958; Henoch 1971), while a glacier physics investigation was done on the Penny Ice Cap, Baffin Island (Ward, 1955). The surface hydrology of permafrost was summarized by Dingman (1971) and Church (1974), while in situ observations and cursory measurements were made in permafrost areas in the early half of the twentieth century by the Cold Regions Research and Engineering Laboratory (CRREL), USA (Sellmann, 1967). With these early research works on glaciers, frozen ground, snow cover, or other elements, corresponding studies on glacier hydrological processes and snow hydrology were performed, and a discipline system based on the methodology of different elements of the cryosphere was gradually formed, including glacier hydrology (Yang, 1991), snow hydrology (DeWalle and Rango, 2008), and permafrost hydrology (Woo, 2012). They either belonged to a branch of glaciology or became a special part of hydrology. 
In these studies, water issues related to cryosphere elements were often attributed to cold region hydrology (Yang et al., 2000) or permafrost hydrology (Woo, 2012). However, the term cold region hydrology was used in a broad sense and lacks scientific definition. Sometimes, cold region hydrology is limited to the hydrology of the permafrost region (Yang et al., 2000; Woo, 2012). Generally, it refers to hydrology in cold regions, including the hydrological phenomena of glaciers, frozen ground, and snow cover, as well as river and lake ice (Woo, 2008; Ding et al., 2017). Studies on multi-element hydrological phenomena of the cryosphere are sometimes also expressed as permafrost hydrology, particularly by Canadian scholars (Woo, 2012). Whether called permafrost hydrology or cold region hydrology, the research subjects concentrate on the hydrological issues of a certain cryosphere element. The discipline system inherits the respective disciplinary characteristics of each single cryosphere element and focuses on the intersection of individual cryosphere elements. In terms of research content and disciplinary structure, they are the same as the subject on a single element of the cryosphere, such as glacier hydrology and snow hydrology. The combined effect of different elements of the cryosphere at basinal, regional, and global scales were rarely addressed.

With the recent development of cryospheric science and the increasing socioeconomic demand for water resources from the cryosphere for global sustainability, research within the cryohydrology discipline urgently requires a transition from the traditional single element perspective to a multi-element, integrated, comprehensive view. Therefore, integrating cryosphere water issues into one research framework and building its disciplinary system from a perspective of cryospheric science is inevitable. In this discipline system, the hydro-thermal processes related to glaciers, frozen ground, snow cover, and lake ice, and the hydrological function of the cryosphere elements need to be considered within the same framework.

Therefore, cryohydrology can be seen as both a traditional and an emerging discipline. Traditionally, the theory and methodology of mass balance, ablation, hydrothermal processes, and generation and convergence mechanisms of single cryosphere elements are the theoretical basis of cryohydrology. However, owing to the increasing impact of global warming on the cryosphere, the hydrological processes and influences of cryosphere elements are receiving broader attention. Water issues related to the cryosphere can no longer be understood separately from the traditional hydrology of a single cryosphere element. It is necessary to move to a cryospheric science perspective, thereby promoting the formation of the cryohydrology discipline.

\section{Relationship Between Cryohydrology and Cryospheric Science}

Cryospheric science studies the formation and evolution of the cryosphere, as well as the interactions between the cryosphere and other spheres of the environment, particularly the impacts of the cryosphere on the rest of the environment and adaptation mechanisms (Qin et al., 2017; Qin et al., 2018). Cryospheric science includes: i) the mechanisms of formation, development and evolution of cryosphere elements, and their interactions; ii) the interaction between each element and the whole cryosphere, and other earth spheres including atmosphere, hydrosphere, lithosphere, and biosphere, among which the intersection of cryosphere and hydrosphere focus on the water cycle and water availability (Figure 1A); and iii) the impact and risk of cryospheric change on other earth spheres, including the relationship between the cryosphere and social sustainable development, particularly adaptation and countermeasures to address cryospheric changes at global and regional scales (Qin et al., 2018). Cryohydrology is accompanied by the simultaneous development of cryospheric science, and several of its research fields are closely related to the elements of cryospheric Science. From the perspective of hydrology, the hydrological effect, water cycle, and water resources of the cryosphere elements are the focus of cryohydrology.

The research tree of cryohydrology is highly similar to that of cryospheric science, and the research contents of cryohydrology make up a part of cryospheric science. In the cryospheric science discipline system, cryohydrology is located together with the impacts of water availability, sea level, and thermohaline circulation at the applied basic research level (Figure 1B). The formation mechanism and changes in cryosphere elements at the basic research level are the scientific basis for cryohydrology. The service, adaptation, and sustainability of water availability, and sea level change at the applied research level are the outputs of cryohydrology (Figure 1B).

\section{Scope of Cryohydrology and Cold Region Hydrology}

Among the cryosphere elements, except for some unstable snow cover (snow days less than two months) and short-term frozen ground (freezing periods less than fifteen days), most elements are stable and generally persist long-term. There is no commonly accepted definition for cold regions. They generally refer to highlatitude or high-altitude regions. Therefore, hydrological research in these regions has generally been called cold region hydrology (Yang et al., 2000).

The cold region can be regarded as the core area affected by the cryosphere, but does not represent its full extent, which is significantly larger. Theoretically, cryohydrology research involves all hydrological phenomena and laws in all extents, including the core area and impact area of the cryosphere, but cold region hydrology primarily involves water issues in the core areas of the cryosphere. Both cryohydrology and cold region hydrology concentrate on cryosphere elements with active hydrological functions and their impacts, thus from this perspective cold region hydrology and cryohydrology are the same.

The major difference between cold region hydrology and cryohydrology is that cold region hydrology focuses more on the special hydrological process of different cryosphere elements, including parts of or all the research methods, processes/ mechanisms, basinal functions, and global/regional impacts (Figure 2). But cryohydrology focuses more on the common 


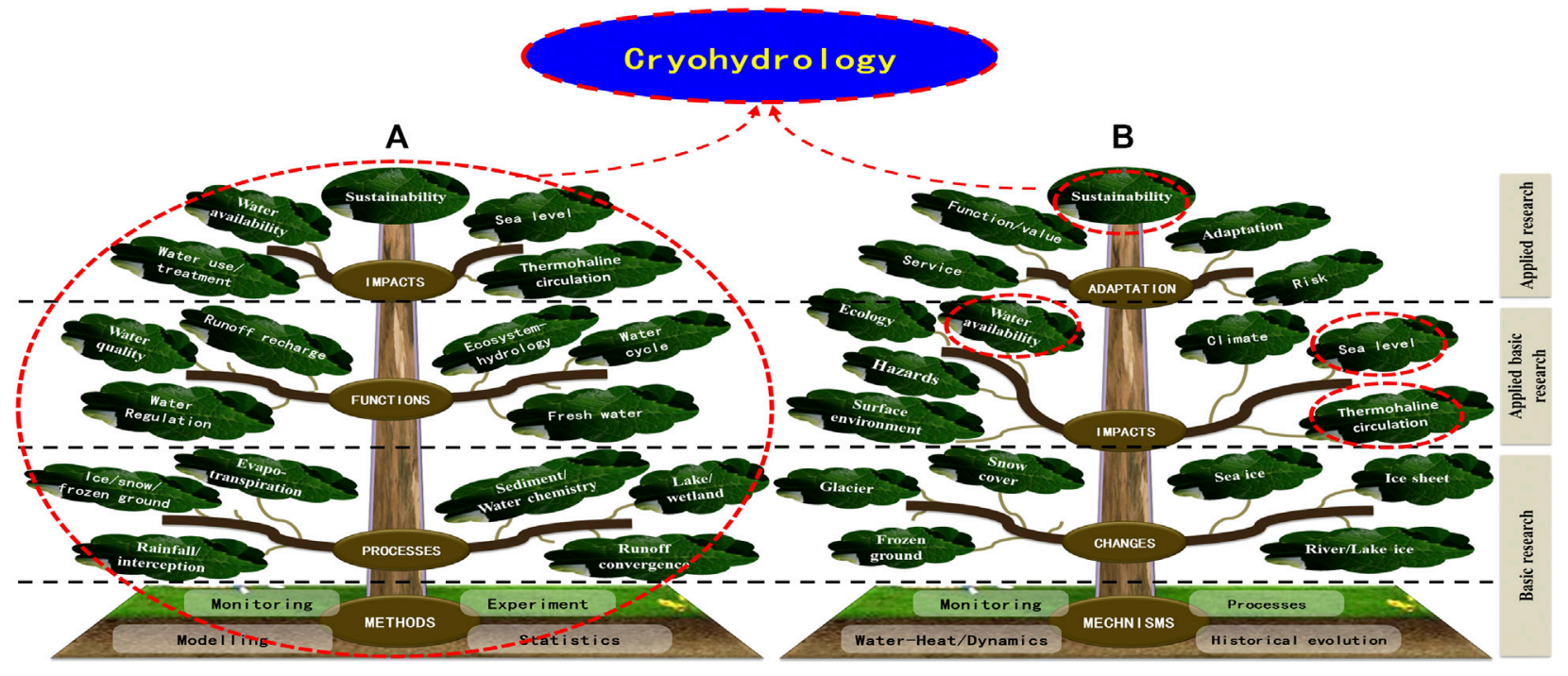

FIGURE 1 | Research content tree of hydrology (A) and (B) cryospheric science (after Qin et al., 2018) as well as and the relationship between hydrology, cryohydrology, and cryospheric science. Note that cryohydrology focuses on the water cycle and water availability, and the intersection between cryospheric science and hydrology.

characteristics of different cryosphere elements, such as the research methods of all cryosphere elements including ice shelf/iceberg, sea ice, snow cover, frozen ground, glacier/ice sheet, and the combined impact of all the elements at the basinal/global scale (Figure 2). For example, the study of the importance and vulnerability of the world's water towers (Immerzeel et al., 2019) concerns not only their watersupplying role in the cryosphere's core area, but also the downstream dependence of the ecosystem and society in the cryosphere's impact areas. This is typical of a cryohydrology study, but not a typical study of cold region hydrology.

Therefore, cold region hydrology studies focus on single cryosphere elements from a vertical perspective of method, process, and impact, while cryohydrology plays with the common cryosphere hydrological law of associated cryosphere elements as much as possible. For example, in cold region hydrology, glacier, permafrost, snow, river/lake ice, and sea ice are all affected by water formation (generation and convergence processes), change (increased and decreased ice volume), and impact (the function of runoff and water resources in basins, regions, and the world) (Figure 2). However, in the cryohydrology discipline system, the hydrothermal processes and hydrological functions in basins related to glaciers, frozen ground, snow, and river ice are studied within one framework (Figure 2). In addition, the cold region has area attributes, and its scope and boundaries are blurred, thus, the scientific concept of cold region hydrology is not as explicit as cryohydrology.

\section{HYDROLOGICAL BASIS OF CRYOHYDROLOGY}

The hydrological functions of different cryosphere elements and their integrated basinwide impacts are the basis of cryohydrology.
They are primarily manifested as water conservation, runoff recharge, and water resource regulation.

\section{Water Conservation}

The water conservation function of cryohydrology includes two main aspects: the source of freshwater, and the cold and wet island effect. Owing to the intrinsic nature of high altitudes or high latitudes, the cryosphere is the birthplace of several of the largest rivers in the world. Several rivers originate from the high altitudes and mountains of North America, the South American Andes, Northern Europe, Siberia, the Alps, and Central Asia. Water from the cryosphere has a significant impact on the sustainable use of water resources in these areas and their downstream basins and were thus called the "water towers" (Immerzeel et al., 2019). The Qinghai-Tibet Plateau, which is also called the Asia's water tower, is the source of the Yangtze River, Yellow River, Tarim River, Nu River, Lancang River, Yili River, Irtysh River, Yarlung Zangbo River, Indus River, Ganges River, etc. (Ding et al., 2017; Yao et al., 2019). The total snow melt contribution across the full basins above $2000 \mathrm{~m}$ is between 65 and $72 \%$ for the Syr Darya, Amu Darya, Indus, and the Brahmaputra, and $43 \%$ for the Ganges (Armstrong et al., 2019). Freshwater sources in cryohydrology are different from rainfall runoff sources. A frozen water source converts solid water to liquid water, and releases past water storage. The cryosphere is a natural reservoir that contains frozen stock which accumulates water during the cold season and releases water during the warm season when water demand is high. The reduction of water storage volume requires long-term climate fluctuations. Therefore, the freshwater sources function of cryohydrology to some extent provides permanent and inexhaustible water sources. The renewal cycle of different elements of cryohydrology is varied. Glacier renewal cycles take hundreds to thousands of years, while ice sheet and permafrost cycles take an even longer 


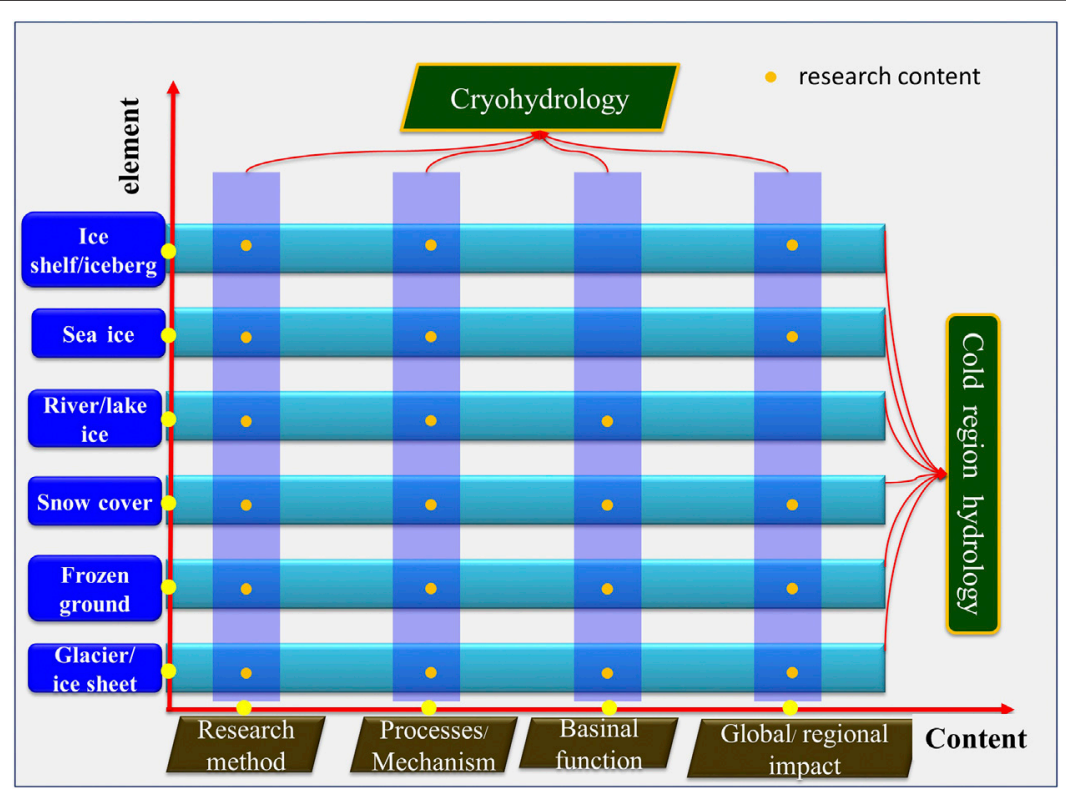

FIGURE 2 | Scope of cryohydrology and cold region hydrology. Note that cryohydrology focuses on the common hydrological law of different elements of the cryosphere, while cold region hydrology focuses on the content of the research method, processes/mechanism, basinal function, and global/regional impact of the single element of the cryosphere.

period of time. Therefore, while the cryosphere constantly receives material supplies, its melting water also consumes past accumulations. The release of historical accumulated water depends on the mass gain or loss status of the elements of the cryosphere. Under the influence of continuous warming, the cryosphere is in negative mass balance, which indicates that it has less water storage. The freshwater source function thus becomes more important under a warming world, particularly when river runoff is projected to decrease.

Another aspect of water conservation is the cold and wet island effect, which has not been fully addressed. As a widely distributed cold sphere (cold island), the cryosphere changes the temperature and humidity field and circulation patterns of the region. It can effectively trap and condense water vapor to form more local precipitation, thereby forming a local cold and humid micro environment of climate (wet island) and strengthening the horizontal turbulence and intensifying the internal turbulence field, which effectively conserves water sources (Ding and Zhang, 2018; Chen et al., 2019). In the meantime, the local convection of endorheic river basins is strengthened, and the recycled moisture over downstream deserts like the Gobi was possibly transported to the alpine region through atmospheric water vapor cycling. This increases the precipitation in alpine regions and strengthens the wet island effect of the high mountain area (Chen et al., 2019).

For example, the upper reach of Hei and Shule river basins in China's Qilian Mountains are primarily composed of glaciers, alpine cold desert, alpine meadow, and alpine steppe permafrost regions. The runoff from the Hei river was simulated by a distributed heat-water coupled (DWHC) model (Chen et al., 2008), while the runoff from the Shule river was simulated by a variable infiltration capacity (VIC-CAS) model that coupled a glacier scheme with a VIC-3L model (Zhao et al., 2015; Zhang and Sheng, 2019). Modeling results suggest that the glacier-alpine cold desert-alpine meadow and steppe of the two basins contribute more than $85 \%$ of the total runoff for the entire basin. The isotope trace method also proved that $80.2 \%$ of the annual total mountainous runoff was generated at the alpine permafrost-snow-ice zone at an altitude of above $3600 \mathrm{~m}$ a. s. 1 . (Wang et al.,2009). The annual precipitation over a glacier is nearly twice that over forests and shrubland, both in the Hei and the Shule river basins, which is consistent with the reported results that precipitation in the cryosphere and plain regions of the endorheic basin in arid regions of China can differ by 5-10 times (Yang, 1991; Ding, 1992; Chen et al., 2018). These phenomena are difficult to explain by large-scale circulation, it can only be explained by the cold and humid island effect of cryohydrology. However, the cold and wet island effect of cryohydrology still needs further quantitative study from the inter-discipline of climatology and hydrology.

\section{Runoff Recharge}

A well-known hydrological function of cryohydrology is runoff recharge. As a solid water reservoir, the cryosphere is an important freshwater resource. The resource attributes are expressed in terms of total storage volume and annual melting recharge. Reservoirs store ice present in the cryosphere and participate in river runoff and ocean circulation by melting from their frozen state. The annual river recharge by the cryosphere is an important component of land surface runoff. 
Approximately $68.7 \%$ of global freshwater resources are stored in the cryosphere, with glaciers and ice sheets most dominant. The ice storage in both the Antarctic and Greenland ice sheets, and mountain glaciers are approximately 56.6, 7.3, and $0.4 \%$ of global freshwater, respectively. The annual maximum water equivalent of snow in the northern hemisphere is approximately $3 \times 10^{3} \mathrm{~km}^{3}$ (IPCC, 2013), and one recent research suggested that the seasonal snowpack pool is between 2.6 and $3.5 \times 10^{3} \mathrm{~km}^{3}$ (Abbott et al., 2019). Based on the Second Chinese Glacier Inventory (SCGI), China has 48,571 glaciers with a total area of $51,770 \mathrm{~km}^{2}$, accounting for approximately $7.1 \%$ of the world's glacier area (except for Antarctica and Greenland ice sheets), with ice reserves of $4,500 \mathrm{~km}^{3}$ (Liu et al., 2015). The ground ice in the permafrost of China's Tibetan Plateau has been estimated as $9,530 \mathrm{~km}^{3}$ (Zhao et al., 2010). According to the latest survey data, the ground ice content in the Tibetan Plateau has been updated to $12,700 \mathrm{~km}^{3}$ (Zhao et al., 2019), which is 2.8 times the ice storage in glaciers. Snow cover in China is primarily concentrated in Xinjiang, the Qinghai-Tibet Plateau, and in northeast China. The annual maximum snow water equivalent of the three snow covered areas is approximately $960 \times 10^{8} \mathrm{~m}^{3}$, or approximately $10 \%$ of the average annual runoff of the Yangtze River (Li et al., 2008).

On a global scale, different cryosphere elements influence the hydrological processes and water cycle on land surfaces and in the ocean in various ways. Arctic sea ice and snow meltwater greatly exceed water in the precipitation-evaporation processes of the Antarctic and Arctic oceans beyond $60^{\circ}$ latitude. They significantly affect the strength of deep-water convection and thereby ocean thermohaline circulation. The contributions to sea level rise of thermal expansion by ocean warming of the cryosphere are nearly stable since industrialization began, if we ignore the impact of changes in land water storage. The projected contribution to global average sea level rise from the cryosphere will exceed that of thermal expansion (Ding and Zhang, 2015). At a regional scale, the cryosphere affects the seasonal distribution of river discharge under changed climate. For example, in the snowmelt-dominated Kelan River basin in the Altai mountains in China, the seasonal distribution of river discharge has changed in the last few decades. The permafrost degradation has significantly affected runoff regulation of the ratio of winter runoff to annual runoff. The ratio of maximum monthly runoff (Qmax) and minimum monthly runoff (Qmin) had changed both in the Arctic and in China. The glacier runoff in several regions has changed. For example, the estimated glacier runoff in China by a modified monthly degree day model (Zhang et al., 2012) has increased during the past 50 years.

The average annual glacial meltwater runoff in China was estimated to be $630 \times 10^{8} \mathrm{~m}^{3} \mathrm{yr}^{-1}$, from 1962 to 2006 (Ding et al., 2017), which is approximately $2.2 \%$ of the total river runoff in China and is more than the average annual runoff of the Yellow River flowing into the sea. It is equivalent to $10.5 \%$ of the total river runoff $\left(5,760 \times 10^{8} \mathrm{~m}^{3} \mathrm{yr}^{-1}\right)$ of Gansu, Qinghai, Xinjiang, and Tibet in Western China. Several rivers are supplied by $15-25 \%$ of the runoff from snowmelt in Northern China $(\mathrm{Hu}$, 2013). The contribution of snowmelt runoff recharge to river discharge in northern Xinjiang, particularly the Altai mountains, reaches $60-70 \%$ in comparison to $40 \%, 20-25 \%, 15-20 \%$ of the basins in the Tianshan and the Qilian Mountains, and the Tibetan Plateau, respectively.

This indicates that changes in the cryosphere will inevitably affect the global water cycle, basinal or regional hydrological processes, and water resource utilization.

\section{Water Resource Regulation}

Compared to the water conservation and runoff recharge functions, the hydrological regulation of cryohydrology is more important. Elements of the cryosphere such as glaciers, snow, and frozen ground regulate the basin wide runoff process in different ways on seasonal, interannual, and interdecadal scales, influencing the use of water resources downstream. Glaciers have a function in both seasonal and interdecadal runoff regulation. The freeze-thaw process impacts the seasonal runoff generation and convergence processes of the basin, while the changes in ground ice can affect the runoff and water resources for a very long period. Snow cover primarily affects the seasonal runoff distribution. At the basinal scale, the regulatory effect of cryohydrology is primarily reflected in its combined effect with rainfall runoff in mountainous areas, its regulating role in river basin runoff by reducing drought, as well as flood mitigation effects in different seasons and years (Ye et al., 2012; Ding and Zhang, 2018).

The interdecadal and seasonal regulation of glaciers on runoff is primarily reflected in solid reservoirs. The glaciers determine the amount of meltwater based on the water (rainfall) and heat (ablation) conditions of the basin to regulate the basin runoff process at the seasonal scale. In this manner, the river runoff in basins with glaciers remains relatively stable, which has a significant role in regulating the variation in runoff ( $\mathrm{Ye}$ et al., 2012). This is beneficial for the use of water resources in the downstream oases of arid areas. Studies in the Cascade Mountains in the United States, the European Alps, and the arid regions of China suggest that the coefficient of variation of summer runoff in glacial-covered watersheds is significantly lower than in other areas (Chen and Ohmura, 1990; Ye et al., 1999; Casassa et al., 2009; Moore et al., 2009; Viviroli et al., 2011).

This regulatory capacity is related to glacier coverage in the watershed. When the glacial coverage of a given watershed exceeds 5\% (Casassa et al., 2009; Ye et al., 2012), the regulation of glacial meltwater runoff on river runoff is significant. It primarily reduces the variation in annual runoff and decreases the annual runoff variation coefficients of the basin. Similar studies (Collins, 2006; Stahl and Moore, 2006) also demonstrate that intra-annual runoff changes in the basin decrease with increasing glacier coverage in basins with only $2-3 \%$ glacial coverage. When glacial coverage reaches $30-40 \%$, runoff tends to be stable, but when it is higher than $40 \%$, the variation in river runoff tends to increase (Bayard et al., 2005).

Snow cover primarily affects the seasonal distribution of river runoff. Snow has a seasonal regulation and storage function, which can temporarily accumulate a certain amount of water. The curves of the snowmelt runoff process are gentler than those of the rainfall runoff process, thereby altering the rainfall runoff 
process of the basin and achieving the effect of regulating runoff. In addition, in cryospheric basins, when precipitation is abundant, solid precipitation formed at high altitudes slows the peak runoff in the form of snow, then melts after precipitation, which regulates runoff to some extent. In the alpine areas of the basin, there is more snowfall in summer with short-term accumulation, which generally affects the generation and convergence processes of river runoff.

The regulatory effect of frozen ground primarily appears as the influence of the freezing and thawing processes on runoff. These processes change the generation and confluence processes of the basin at the interannual scale, while variations in ground ice can affect the runoff and water resources of the basin for a longer period. The runoff generated from precipitation and snowmelt tends to be larger under the influence of the barrier of the frozen ground, leading to the generation of high runoff even when the precipitation is low. In summer, seasonally frozen ground melts. An active layer of permafrost also gradually melts and the lower limit of the active layer descends to a deeper location. The profile of soil moisture increases with depth, extending to deeper soil in active layers. The underground water table over permafrost declines, while the total water storage capacity of soil increases. The melting permafrost and seasonally frozen ground promotes the water storage capacity of the basin, increases evapotranspiration, and regulates runoff by cutting flood peaks. Existing studies (e.g., Bayard et al., 2005; Gibsona et al., 2011; Kalyuzhnyi and Lavrov, 2012; Liljedahl et al., 2016; Melissa and Scott, 2019; Yang et al., 2019; Huissteden van, 2020) have suggested that under climate change, permafrost will degrade by deepening the thickness of the active layer, which will increase soil water storage space, and thereby increase the amount of water from summer precipitation stored in the active layer of permafrost, leading to a prolonged convergence time of runoff. In the Arctic region, the thick ground ice in the permafrost melts and recharges to river runoff or to lakes, with climate warming. This may lead to an increase in winter (dry season) runoff in permafrost regions, a decrease in summer runoff, and a slower interannual runoff process. The intensity of change is related to the permafrost coverage of the basin.

\section{DISCIPLINE SYSTEM OF CRYOHYDROLOGY}

\section{Research Content}

Cryohydrology's discipline mainline has a method-process function-impact, and its core research issues can be sorted out along this mainline (Figure 3).

The research methods can be summarized as field observation and experiments, laboratory experiments and analysis, remote sensing and geographic information system applications, and mathematical statistics and model simulation.

These processes and changes are the mechanisms of cryohydrology research. The process involves three major aspects: 1) the melting, runoff generation, and convergence process, 2) the runoff change process, and 3) sediment and water chemistry. The melting, runoff generation, and convergence process includes snow/ice accumulation and melting, snow/ice meltwater convergence, frozen ground freeze/melt runoff generation and convergence, river/lake/sea ice generation and migration. The runoff change process includes characteristics of different supply to cryospheric rivers, the cryospheric meltwater runoff process, and cryospheric meltwater runoff projection. Sediment and water chemistry include river sediment changes, the water chemistry process, biogeochemical processes, and the application of water chemistry.

Cryohydrology is hydrologically crucial at the basin scale. Its functions include water conservation, river runoff recharge, regulation of water resources, and alleviation of extreme hydrological events.

Cryohydrology's main impact is in its output to other spheres. The above research issues in method, processes, and function are primarily related to the hydrological characteristics of cryosphere elements. For example, a recent study (Musselman et al.,2018) suggested that rain-on-snow becomes more frequent at higher elevations where seasonal snow cover persists due to a shift from snowfall to rainfall, with correspondingly increases the flood risk by $20-200 \%$ over North America. When the meltwater flows into the catchment, it mixes with rainfall runoff. In different parts of the basin, owing to the proportion of the meltwater runoff and the impact of the coverage of frozen ground being different, the impact of the cryosphere on river runoff varies. The impact of cryohydrology includes cryospheric and fresh water within river basins, the cryosphere as part of the global water cycle, and the cryosphere as part of sea level rise.

\section{Discipline Characteristics}

The core characteristic of cryohydrology is the phase change of water. The largest difference between cryohydrology and traditional hydrology is the frequent phase transitions between the vapor-liquid-solid states of water and the associated changes in water, energy, mass, and solute during the phase transition. Owing to the large energy exchange during the water phase change, the phase transition further affects the interactions between the atmosphere, cryosphere, hydrosphere, biosphere, and even the lithosphere. The phase transition is the link between cryohydrology and other processes in cryospheric science. Their high sensitivity to climate change is a common characteristic of the cryosphere elements, and the hydrological processes of different cryosphere elements have varied response patterns, with complicated response processes. In a specific basin, different elements of the cryosphere act together on river runoff, resulting in river runoff being very sensitive to climate change. To accurately predict runoff changes in the cryospheric basin, multisource data, multiple experimental measures, multiple models, and multiple perspectives must be used together to project the future changes of different cryosphere elements, as well as their impact on hydrological processes.

Field observations and experiments are an important characteristic of cryohydrology. The harsh natural environment makes field observation difficult, resulting in very 


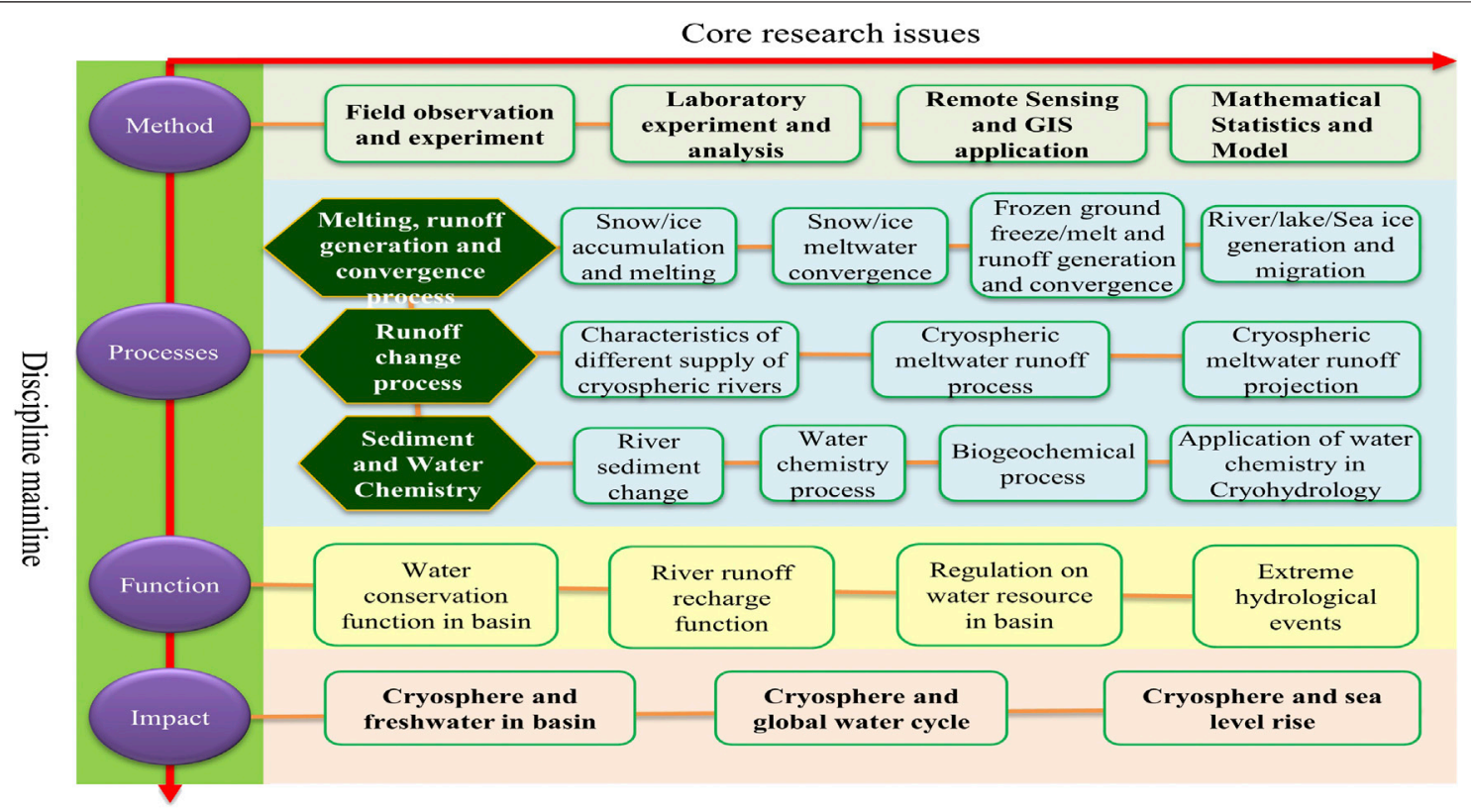

FIGURE 3 | The core research issues of cryohydrology along the discipline mainline which primarily include method (in situ observation, laboratory experiment, remote sensing application, and statistics/model), processes (melting, runoff generation and convergence, runoff changes, and sediment and chemistry), function (water conservation, runoff recharge, regulation, and extreme events), and impact (freshwater in basin, global water cycle, and sea level rise).

limited experimental data obtained for research. Meanwhile, cryohydrology not only requires consideration of the water cycle and water balance between different cryosphere elements at different scales, but also the energy and mass balances between them. Therefore, cryohydrology researchers need to conduct several field observations and multi-measurement experiments to satisfy the requirements of high quality in situ observations and experimental data.

The surplus effect is another important characteristic of the discipline. Cryohydrology not only studies the hydrological processes of the cryosphere itself, but also considers the hydrological impact on other regions outside the cryosphere. This surplus feature affects basins, regions, and even the world. The understanding of cryohydrologic processes on the formation of water resources in related regions, the hydrological functions of different components, and the potential changes of different components under future climate change scenarios are closely related to short-term, medium-term, and long-term sustainable development. One characteristic of cryohydrology is that it is the intersection of several of these disciplines. From the perspective of the mechanism, cryohydrology is a close intersection of cryospheric science, hydrology, geography, and atmospheric science. The phase transition processes of water and related water chemical processes are closely related to traditional physics and chemistry. The study of the regional and global impact of the water cycle is also closely related to social science, such as sustainable development and economics.

The last characteristic of cryohydrology is its varied temporal and broad spatial scale. Depending on the content of study, the temporal scale involved in cryohydrology ranges from hours to hundreds of years (Figure 4). When research issues focus on the process/mechanism, the temporal scales vary from hours to hundreds of years, with a daily or monthly scale as the general one. For example, the temporal scale of one extreme hydrological event such as a moraine-dammed lake outburst flood is generally between hours to days. When researching basinal function, the temporal scale always ranges from one to hundreds of years. For example, the intensity and frequency of extreme hydrological events probably changes under climate change, and its impact on basin also varies. When focus is on the impact of the cryosphere's freshwater cycle on the ocean, the temporal scale can reach up to a millennial scale or even longer. The spatial scales of cryohydrology range from points to global scales. The process/mechanism is generally carried out at a point/slope/field scale. The hydrological function is analyzed mostly at the basinal scale, and the impact of cryohydrology is generally illustrated at the regional/global scale (Figure 4). Our study found that the time scale generally increases with the expansion of the spatial scale.

\section{Relationship Between Cryohydrology and Other Disciplines}

The basis of the cryohydrology discipline comes from other related specialties. Based on the existing research foundation and scientific understanding, energy balance and water balance are the physical basis of cryohydrology and are the most basic theoretical foundation supporting its development. (Figure 5). In terms of the energy 


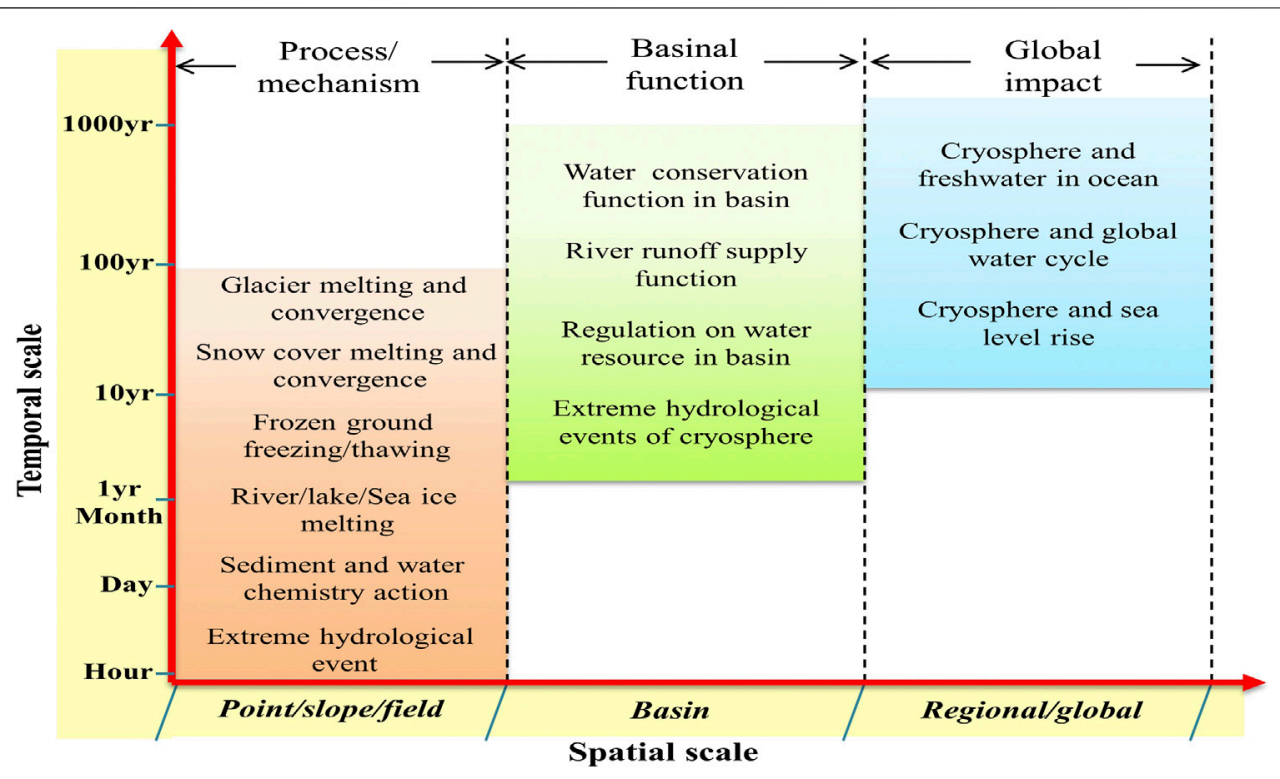

FIGURE 4 | Difference of main research contents of cryohydrology at the temporal (hour, day, month, year, and more than 1,000 years) and spatial (point/slope/ field, basin, and region/global) scales.

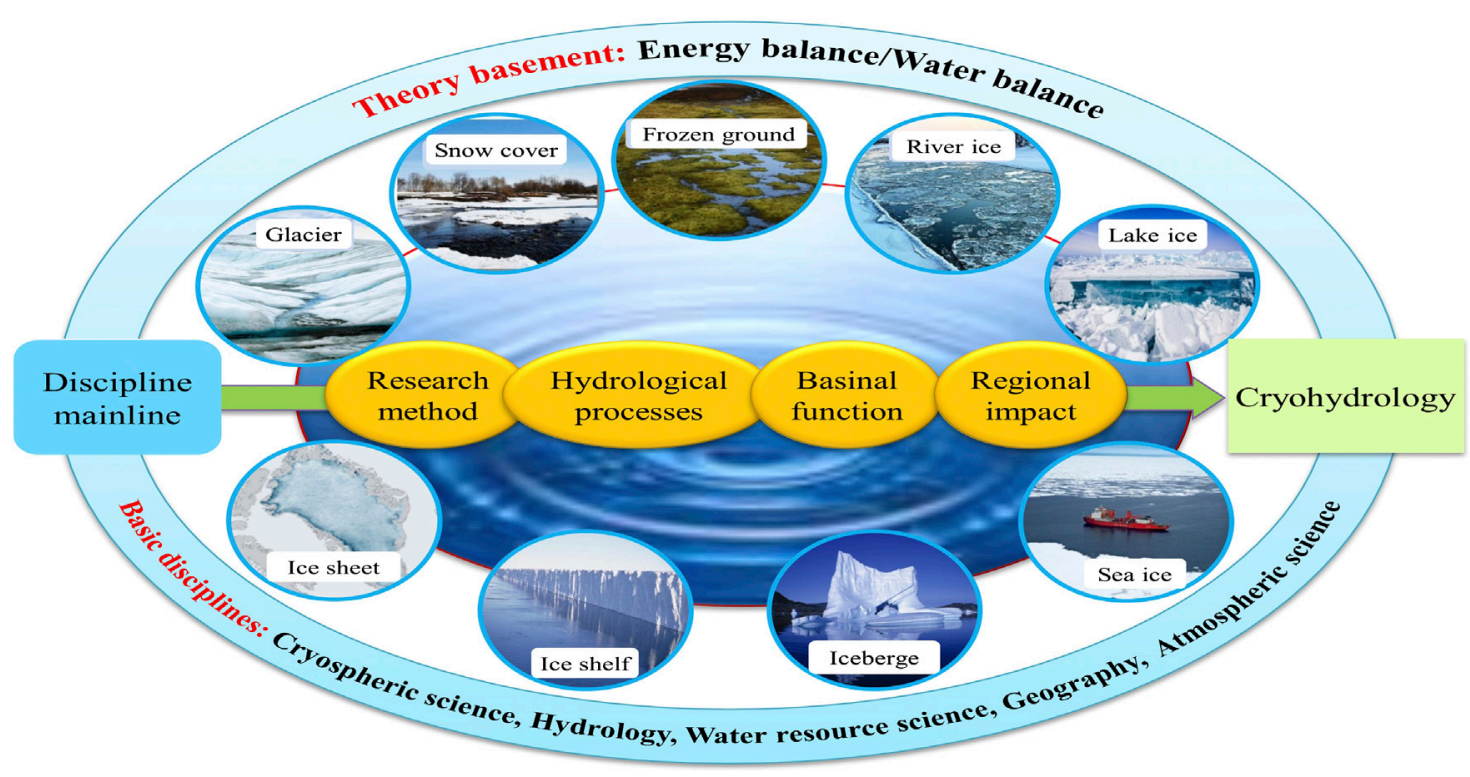

FIGURE 5| The theory basis and basic disciplines of cryohydrology along the mainline from method, processes, and function to impact of different elements of the cryosphere.

balance theory, cryohydrology is more related to cryospheric science and atmospheric science, while water balance is more related to hydrology and water resource science. Thus, the most important basic disciplines of cryohydrology are cryospheric science and hydrology (Figure 1). Meanwhile, water resource science, geography, and atmospheric science are also inseparable from cryohydrology. These are all its important basic and foundational disciplines (Figure 5).
From this view, glaciers, snow cover, frozen ground, river ice, lake ice, sea ice, ice sheets, ice shelves, icebergs, and other elements of the cryosphere can be considered as research objects in cryohydrology; using energy balance and water balance as the theoretical basis; utilizing research methodhydrological process-watershed effect-regional impact as the mainline basis for research; and using these to conduct hydrological research on the cryosphere. The objectives of 
cryohydrology are to understand the hydrological processes, clarify the hydrological functions, and understand the hydrological impacts on the society of the cryosphere.

\section{SUMMARY AND PERSPECTIVE}

This study attempts to introduce the hydrological basis and discipline system of cryohydrology from the integrated view of cryospheric science. Several conclusions were made as follows:

(1) Cryohydrology was developed based on traditional hydrology for a single element of the cryosphere and focused on the hydrological functions of the cryosphere and its impact on the water cycle and water availability of other spheres. As a discipline with significant traditional inheritance, cryohydrology needs to be further improved both in the theory of the discipline system and in the integration and systematization of the discipline.

(2) The hydrological function of cryohydrology includes water conservation, runoff recharge, and hydrological regulation. The water conservation function is primarily expressed as "freshwater source" and "cold and wet islands effect". The runoff recharge function is primarily in the supply of water, and the regulation function is primarily concerned with the intra-annual and inter-annual scales.

(3) The core research issues of cryohydrology are along the mainline of research methods, hydrological processes, watershed functions, and regional impact. The most important characteristic of cryohydrology is frequent water phase transitions at highly variate spatial and temporal scales.

\section{REFERENCES}

Abbott, B. W., Bishop, K., Zarnetske, J. P., Minaudo, C., Chapin, F. S., III, Krause, S., et al. (2019). Human domination of the global water cycle absent from depictions and perceptions. Nat. Geosci. 12, 533-540. 10.1038/s41561-0190374-y

Armstrong, R. L., Rittger, K., Brodzik, M. J., Racoviteanu, A., Barrett, A. P., Singh Khalsa, S.-J., et al. (2019). Runoff from glacier ice and seasonal snow in High Asia: separating melt water sources in river flow. Reg. Environ. Change 19 (5), 1249-1261. doi:10.1007/s10113-018-1429-0

Bavay, M., Grünewald, T., and Lehning, M. (2013). Response of snow cover and runoff to climate change in high Alpine catchments of Eastern Switzerland. Adv. Water Resour. 55, 4-16. 10.1016/j.advwatres.2012.12.009

Bayard, D., Stähli, M., and Parriaux, A., FlühlerFlühler, H. (2005). The influence of seasonally frozen soil on the snowmelt runoff at two Alpine sites in southern Switzerland. J. Hydrol. 309 (1-4), 66-84. 10.1016/j.jhydrol.2004.11.012

Biemans, H., Siderius, C., Lutz, A. F., Nepal, S., Ahmad, B., Hassan, T., et al. (2019). Importance of snow and glacier meltwater for agriculture on the Indo-Gangetic Plain. Natural Sustainability 2, 594-601. 10.1038/s41893-019-0305-3

Casassa, G., López, P., Pouyaud, B., and Escobar, F. (2009). Detection of changes in glacial runoff in alpine basins: examples from North America, the Alps, central Asia and the Andes. Hydrol. Process. 23, 31-41. 10.1002/hyp.7194

Chen, J. and Ohmura, A. (1990). "On the influence of Alpine glaciers on runoff," in Hydrology in mountainous regions I-hydrological measurements: the water cycle (Wallingford, UK: IAHS Publication), 193, 117-125.

Chen, R., Han, C., Liu, J., Yang, Y., Liu, Z., Wang, L., et al. (2018). Maximum precipitation altitude on the northern flank of the Qilian Mountains, Northwest China. Nord. Hydrol 49 (5), 1696-1710. 10.2166/NH.2018.121
Cryohydrology is not only of great significance to accurately understand and project the hydrological changes of river basins and the sustainable use of water resources. It also plays an important role in understanding the ecological and hydrological effects at the basin scale, and relevant changes in the geographic environment. However, these effects have not been fully addressed. Based on enhanced observations and experiments, the future development of cryohydrology should deepen the theoretical and cognitive levels of its mechanisms and processes. It should accurately quantify the hydrological functions on a basin scale (particularly the hydrological regulation of water resources), as well as its effects on the environment and ecosystem. It also should strengthen future research on the process and mechanism of the cryosphere's influence on the ocean.

\section{AUTHOR CONTRIBUTIONS}

YD and SZ designed the research, YD, SZ, RC, TH, HH, JW, XL, QZ, DS, YY, JL, SW, JQ, and YC performed the research and writing the draft; YD, SZ, and XL revised the draft.

\section{ACKNOWLEDGMENTS}

This work was supported by the National Natural Science Foundation of China (41730751, 41671056). A special acknowledgment should be expressed to China-Pakistan Joint Research Center on Earth Sciences that supported the implementation of this study.

Chen, R., Lu, S., Kang, E., et al. (2008). A distributed water-heat coupled model for mountainous watershed of an inland river basin of Northwest China (I) model structure and equations. Environ. Geol. 53 (6), 1299-1309. 10.1007/s00254-0070738-2

Chen, R., Zhang, S., and Yang, Y. (2019). Impact of cryosphere change on runoff of cold regions in Western China. Beijing: Science Press.

Church, M. (1974). "Hydrology and permafrost with reference to northern North America," in Proc. Workshop seminar on permafrost hydrology. Ottawa: Can. Nat. Comm.IHD, 7-20.

Collier, E. P., (1958). "Glacier variation and trends in run-off in the Canadian Cordillera," in IAHS Publication 46, Assemble'e Ge'ne'rale de Toronto, 1957, Neiges et Glaces (Wallingford: International Association of Hydrological Sciences), 344-357.

Collins, D. N., (2006). Climatic variation and runoff in mountain basins with differing proportions of glacier cover. Hydrol. Res. 37, 315-326. 10.2166/nh. 2006.017

DeWalle, D. R., and Rango, A. (2008). Principles of snow hydrology. Cambridge: Cambridge University Press.

Ding, Y., Zhang, S., and Chen, R. (2017). Introduction on hydrology in cold regions (in Chinese). Beijing: Science Press.

Ding, Y., and Zhang, S. (2018). Study on water internal recycle process and mechanism in typical mountain areas of inland basins, northwest China: progress and challenge (in Chinese with English abstract). Adv. Earth Sci. 33 (7), 70-78.

Ding, Y., and Zhang, S. (2015). The hydrological impact of cryosphere water cycle on global-scale water cycle (in Chinese). Chin. Sci. Bull. 60, 593-602. 10.1360/ N972014-00899

Ding, Y., (1992). Some glacio-micrometeorological features on the north side of mount qogir(K2), karakoram mountains. Ann. Glaciol. 16, 67-72. 10.3189/ 172756406781812087 
Dingman, S. L. (1971). Hydrology of the glenn creek watershed, tanana basin, central Alaska. U.S. Army CRREL Res. Rep. 297, 110.

French, H., and Slaymaker, O. (2012). Changing cold environments: a Canadian perspective. Hoboken, NJ: Wiley-Blackwell.

Georg, K., Martin, G., and Ben, M. (2010). Contribution potential of glaciers to water availability in different climate regimes. Proc. Natl. Acad. Sci. U. S. A. 107 (47), 20223-20227. 10.1073/pnas.1008162107

Gibsona, J. J., Yib, Y., and Birksb, S. J. (2011). Isotopic tracing of hydrologic drivers including permafrost thaw status for lakes across Northeastern Alberta, Canada: a 16-year, 50-lake assessment. J. Hydrol. 403 (3-4), 352-359. 10. 1016/j.jejr.2019.100643

Henoch, W. E. S. (1971). Estimate of glaciers secular (1948- 1966) volumetric change and its contribution to the discharge in the upper North Saskatchewan River Basin. J. Hydrol. 12, 145-160. 10.1016/0022-1694(71)90106-5

Hu, R. (2013). Snow cover and snow hazard prevention in China. Beijing: China Environmental Science Press.

Huissteden van, J. (2020). Thawing permafrost. Cham: Springer.

Immerzeel, W. W., Lutz, A. F., Andrade, M., Bahl, A., Beimans, H., Bolch, T., et al. (2020). Importance and vulnerability of the world's water towers. Nature 577 (7790), 364-369. doi:10.1038/s41586-019-1822-y

Immerzeel, W. W., van Beek, L. P., and Bierkens, M. F. (2010). Climate change will affect the Asian water towers. Science 328, 1382-1385. doi:10.1126/science. 1183188

IPCC (2013). Climate change 2013: the physical science basis. Cambridge, CA: Cambridge University Press.

Irvine-Fynn, T. D., Hodson, A. J., Moorman, B. J., Vante, G., and Hubbard, A. L. (2011). Polythermal glacier hydrology: a review. Rev. Geophys. 49 (4), RG4002. 10.1029/2010RG000350

Kalyuzhnyi, I., and Lavrov, S. (2012). Basic physical processes and regularities of winter and spring river runoff formation under climate warming conditions. Russ. Meteorol. Hydrol. 37, 47-56. 10.3103/S1068373912010074

Kalyuzhnyi, I., and Lavrov, S. A. (2017). Mechanism of the influence of soil freezing depth on winter runoff. Water Resource 44, 604-613. 10.1134/ S0097807817040078

Li, P., Zhang, Z., and Liu, J. (2010). Dominant climate factors influencing the Arctic runoff and association between the Arctic runoff and sea ice. Acta Oceanol. Sin. 29 (5), 10-20. 10.1007/s13131-010-0058-3

Li, X., Cheng, G., Jin, H., Kang, E., Che, T., Jin, R., et al. (2008). Cryospheric change in China. Global Planet. Change 62, 210-218. 10.1016/j.gloplacha.2008.02.001

Liljedahl, A., Boike, J., Daanen, R. P., Fedorov, A. N., Frost, G. V., Grosse, G., et al. (2016). Pan-Arctic ice-wedge degradation in warming permafrost and its influence on tundra hydrology. Nat. Geosci. 9, 312-318. 10.1038/ngeo2674

Liu, S., Yao, X., Guo, W., Xu, J., Shangguan, D., Wei, J., et al. (2015). The contemporary glaciers in China based on the second Chinese glacier inventory (in Chinese with English abstract). Acta Geographic Sinica 70 (1), 3-16. 10.11821/dlxb201501001

Martinec, J. (1965). "A representative watershed for the research of snowmeltrunoff relations," in International Symposium on representative and experimental watersheds. Budapest, Hungary: IAHS Publ. No. 66, 494-501.

Martinec, J. (1960). "The degree-day factor for snowmelt-runoff forecasting," in IUGG general assembly of helsinki. Budapest, Hungary: IAHS Publ.No. 51, Surface Waters, 468-477.

Masiokas, M. H., Villalba, R., Luckman, B. H., Christie, D. A., Betman, E., Prieto, M. R., et al. (2010). Intra-to multidecadal variations of snowpack and streamflow records in the Andes of Chile and Argentina between $30^{\circ}$ and $37^{\circ}$ S. J. Hydrometeorol. 11 (3), 822-831.

Melissa, J. L., and Scott, F. L. (2019). Effects of changing permafrost conditions on hydrological processes and fluvial fluxes. Earth Science Rev. 191, 212-223. 10. 1016/j.earscirev.2019.02.018

Moore, R. D., Fleming, S. W., Menounos, B., Wheate, R., Fountain, A., Stahl, K., et al. (2009). Glacier change in western North America: influences on hydrology, geomorphic hazards and water quality. Hydrol. Process. 23, 42-61. 10.1002/hyp.7162

Musselman, K. N., Lehner, F., Ikeda, K., Clark, M. P., Prein, A. F., Liu, C., et al. (2018). Projected increases and shifts in rain-on-snow flood risk over western North America. Nat. Clim. Change 8 (9), 808-812. 10.1038/s41558-018-0236-4

National Academy of Sciences (2012). "Himalayan glaciers: climate change, water resources, and water security," in Committee on himalayan glaciers, hydrology, climate change, and implications for water security, board on atmospheric studies and climate division on earth and life studies. Washington, DC: The National Academies Press.

Pellicciotti, F., Carenzo, M., Bordoy, R., and Stoffel, M. (2014). Changes in glaciers in the Swiss Alps and impact on basin hydrology: current state of the art and future research. Sci. Total Environ. 493, 1152-1170. doi:10.1016/j.scitotenv. 2014.04.022

Phillips, T., Rajaram, H., Colgan, W., Steffen, K., and Abdalati, W. (2013). Evaluation of cryo-hydrologic warming as an explanation for increased ice velocities in the wet snow zone, Sermeq Avannarleq, West Greenland. J. Geophys. Res. Earth Surf. 118, 1241-1256. 10.1002/jgrf.20079

Qin, D., Ding, Y., Xiao, C., Kang, S., Ren, J., Yang, J., et al. (2018). Cryospheric science: research framework and disciplinary system. Nat. Sci. Rev. 5 (2), 255-268. 10.1093/nsr/nwx108

Qin, D., Yao, T., and Ding, Y. (2017). Introduction on cryospheric science (in Chinese). Beijing: Science Press.

Sellmann, P. V. (1967). Technical Report 199. Geology of the USA CRREL permafrost tunnel, Fairbanks, Alaska. Hanover, New Hampshire: US Army CRREL, p22.

Singh, P. (2001). Snow and glacier hydrology. Berlin: Springer Science \& Business Media, Vol. 37.

Singh, V. P. (2017). Handbook of applied hydrology. 2nd Edn. McGraw-Hill Education.

Slaymaker, O., and Kelly, R. (2009). The cryosphere and global environmental change. Hoboken, NJ: Blackwell Publishing.

Sorg, A., Bolch, T., Stoffel, M., Solomina, O., and Beniston, M. (2012). Climate change impacts on glaciers and runoff in Tien Shan (Central Asia). Nat. Clim. Change 2 (10), 725-731. 10.1038/nclimate1592

Stahl, K., and Moore, R. D. (2006). Influence of watershed glacier coverage on summer streamflow in British Columbia, Canada. Water Resour. Res. 42, W06201. doi:10.1029/2006WR005022

Steffen, K., Yang, D., and Ryabinin, V. (2012). "ACSYS: a scientific foundation for the climate and cryosphere (CliC) project," in Arctic climate change: the ACSYS decade and beyond. Atmospheric and oceanographic sciences library 43. Editors P Lemke and H. W Jacobi (Dordrecht, Netherlands: Springer), 437-459.

Tang, Q., Lan, C., and Su, F. (2019). Streamflow change on the Qinghai-Tibet Plateau and its impacts (in Chinese with English abstract). Chin. Sci. Bull. 64, $2807-2821$.

US Army Snow Hydrology (1956). Summary report of the snow investigations. Portland, Oregon: North Pacific Division, Corps of Engineers, 437.

Viviroli, D., Archer, D., Buytaert, W., Fowler, H. J., Greenwood, G. B., Hamlet, A. F., et al. (2011). Climate change and mountain water resources: overview and recommendations for research, management and policy. Hydrol. Earth Syst. Sci. 15, 471-504. doi:10.5194/hess-15-471-2011

Wang, N., Zhang, S., He, J. Q., Pu, J. C., Wu, X. B., and Jiang, X. (2009). Tracing the major source area of the mountainous runoff generation of the Heihe River in northwest China using stable isotope technique. Chin. Sci. Bull. 54 (16), 2751-2757. 10.1007/s11434-009-0505-8

Ward, W. H. (1955). Studies in glacier physics on the Penny ice Cap, Baffin island, 1953. Part IV: the flow of highway glacier. J. Glaciol. 2 (18), 592-600. doi:10. 3189/002214355793702082

Woo, M. K. (2008). "Cold region atmospheric and hydrologic studies. The mackenzie GEWEX experience," in Hydrologic process (Springer-Verlag Berlin Heidelberg), Vol. 2.

Woo, M. K. (2019). Cryohydrology in Canada: a brief history. Hydrol. Process. 33 (26), 3407-3411. 10.1002/hyp.13581

Woo, M. K. (2012). Permafrost hydrology. Springer-Verlag Berlin Heidelberg.

Yang, Y., Wu, Q., Jin, H., Wang, Q., Huang, Y., Luo, D., et al. (2019). Delineating the hydrological processes and hydraulic connectivities under permafrost degradation on Northeastern Qinghai-Tibet Plateau, China. J. Hydrol. 569, 359-372. 10.1016/j.jhydrol.2018.11.068

Yang, Z. (1991). Glacier water resources in China (in Chinese). Lanzhou: Gansu Science and Technology Press.

Yang, Z., Liu, X., and Zeng, Q. (2000). Chinese cold region hydrology (in Chinese). Beijing: Science Press.

Yao, T., Thompson, L., Yang, W., Yu, W., Gao, Y., and Guo, X., (2012). Different glacier status with atmospheric circulations in Tibetan Plateau and surroundings. Nat. Clim. Change 2, 663-667. 10.1038/nclimate1580 
Yao, T., Xue, Y., Chen, D., Chen, F., Thompson, L., Cui, P., et al. (2019). Recent Third Pole's rapid warming accompanies cryospheric melt and water cycle intensification and interactions between monsoon and environment: multi-disciplinary approach with observation, modeling and analysis. Bull. Am. Meteorol. Soc. 100 (3), 423-444. 10.1175/BAMSD-17-0057.1

Ye, B., Ding, Y., and Jiao, K. (2012). The response of river discharge to climate warming in cold region over China. Quat. Sci. 32 (1), 103-110.

Ye, B., Han, T., and Ding, Y. (1999). Some changing characteristics of glacier streamflow in Northwest China (in Chinese). J. Glaciol. Geocryol. 21 (1), 54-58.

Ye, K., and Lau, N. (2019). Characteristics of Eurasian snowmelt and its impacts on the land surface and surface climate. Clim. Dynam. 52, 1115-1138. 10.1007/ s00382-018-4180-9

Zhang, S., Ye, B., Liu, S., and Zhang, X. (2012). A modified monthly degree-day model for evaluating glacier runoff changes in China. Part I: model development. Hydrol. Process. 26 (11), 1686-1696. 10.1002/hyp.8286

Zhao, L., Ding, Y., and Liu, G. (2010). Estimates of the reserves of ground ice in permafrost regions on the Tibetan plateau. J. Glaciol. Geocryol. 32 (1), 1-9.

Zhao, L., and Sheng, Y. (2019). Permafrost and changes in Tibetan plateau (in Chinese). Beijing: Science Press.
Zhao, Q., Ding, Y., Wang, J., Gao, H., Zhang, S., Zhao, C., et al. (2019). Projecting climate change impacts on hydrological processes on the Tibetan Plateau with model calibration against the glacier inventory data and observed streamflow. J. Hydrol. 573, 60-81. 10.1016/j.jhydrol.2019.03.043

Zhao, Q., Zhang, S., Ding, Y., Wang, J., Han, H., Xu, J., et al. (2015). Modeling hydrologic response to climate change and shrinking glaciers in the highly glacierized Kunma like River catchment, central Tian Shan. J. Hydrometeorol. 16 (6), 2383-2402. 10.1175/JHM-D-14-0231.1

Conflict of Interest: The authors declare that the research was conducted in the absence of any commercial or financial relationships that could be construed as a potential conflict of interest.

Copyright $\odot 2020$ Ding, Zhang, Chen, Han, Han, Wu, Li, Zhao, Shangguan, Yang, Liu, Wang, Qin and Chang. This is an open-access article distributed under the terms of the Creative Commons Attribution License (CC BY). The use, distribution or reproduction in other forums is permitted, provided the original author(s) and the copyright owner(s) are credited and that the original publication in this journal is cited, in accordance with accepted academic practice. No use, distribution or reproduction is permitted which does not comply with these terms. 